\title{
The High Temperature Performance Evaluation of Polymer/Nanocomposite Modified Asphalt Cement
}

\author{
Mustafa ALAS ${ }^{1}$ \\ Ali Shaban ALBRKA ISMAEL ${ }^{2}$ \\ Hüseyin GÖKÇEKUŞ
}

\begin{abstract}
The current study focuses on the effect of Acrylate-styrene-acrylonitrile (ASA)/Nanosilica (Si) modified binders on the complex modulus $\left(\mathrm{G}^{*}\right)$ and rutting resistance parameters $\left(\mathrm{G}^{*} /\right.$ $\sin \delta$ ) of Asphalt Cement (AC). Four different blends including the base binder and the polymer nanocomposites which were formed by blending 5\% ASA to base binder with the addition of nanosilica at 3,5 and $7 \%$ by the weight were the subject of investigations. Conventional and Dynamic Shear Rheometer (DSR) testing procedures were conducted as well as morphology analysis using Fourier Transform Infrared Spectroscopy (FT-IR). The rheological characteristics of AC were analysed by master curves, isochronal plots and rutting resistance parameter plots. Test results revealed that $\mathrm{G}^{*}$ and $\mathrm{G}^{*} / \sin \delta$ of all modified samples were significantly enhanced compared to the base binder. Multiple Stress Creep Recovery Test (MSCRT) conducted at $100 \mathrm{~Pa}$ and $3200 \mathrm{~Pa}$ showed that, non-recoverable compliance was reduced and elastic recovery of modified binders were improved. Optimum concentration was found to be $5 \% \mathrm{ASA} / \mathrm{Si}$ composite, as further addition of polymer nanocomposite resulted in lower enhancement in the rheological properties of modified AC due to the occurrence of agglomeration between the composite and the base binder.
\end{abstract}

Keywords: Rheological characterization, polymer/nanocomposite, acrylate-styreneacrylonitrile, nano-silica.

\section{INTRODUCTION}

Asphalt cement (AC) is used as the binding agent in the design and construction of flexible pavement roads. The viscoelastic properties of $\mathrm{AC}$ makes it a suitable option as it shows

Note:

- This paper was received on June 30, 2020 and accepted for publication by the Editorial Board on December 11, 2020.

- Discussions on this paper will be accepted by September 30, 2022.

- https://doi.org/10.18400/tekderg.761208

1 Civil Engineering Department, Near East University, Nicosia, North Cyprus, Turkey mustafa.alas@neu.edu.tr - https://orcid.org/0000-0002-8988-2008

2 Civil Engineering Department, Near East University, Nicosia, North Cyprus, Turkey shabarofking10@gmail.com - https://orcid.org/0000-0003-1938-9127

3 Civil Engineering Department, Near East University, Nicosia, North Cyprus, Turkey huseyin.gokcekus@neu.edu.tr - https://orcid.org/0000-0001-5793-4937 
resistance to dynamic vehicular loading and extreme climatic conditions. It is favorable that AC demonstrates stiff behavior at high temperatures and low frequencies to prevent permanent deformation as well as elastic behavior at low temperatures and high frequencies to prevent fatigue cracking failures (1). Additionally, $\mathrm{AC}$ is required to be resistant to aging and it should poses strong adhesion properties for achieving more durable $\mathrm{AC}$ in order to minimizing the maintenance cost and to increasing the service life of pavement (2). Virgin asphalt may not always ensure desired performance across the entire service life. Thus, modification of $\mathrm{AC}$ has become essential to improve the performance characteristics and durability of pavement roads. On this basis, polymers, nanomaterials, and polymer/nanocomposite materials have previously been utilized to modify $\mathrm{AC}(3,4)$.

Polymer modifiers have proven to be effective in enhancing the physical and rheological properties as well as improving the durability of $\mathrm{AC}$, thus reducing the life cycle costs. Polymer modified asphalt is considered to be cost effective, providing that the cost of modification does not exceed the cost of base asphalt by more than $100 \%$ (5). Based on their characteristics, polymers are categorized into different groups. Elastomers and plastomers are the most widely utilized modifiers.

Polyolefin plastomers, such as Polyethylene (PE), polypropylene (PP) and ethylene vinyl acetate (EVA), have been acknowledged in the literature as they improve the high temperature performance of $\mathrm{AC}$ in the prevention of rutting failure (6). Ameri et al., and Brovelli et al., $(7,8)$ studied EVA modified binders by using different penetration grade base asphalt modified at various concentrations. Their findings showed an increase in the rutting parameter $\left(\mathrm{G}^{*} / \sin \delta\right)$ induced by the enhancement in the stiffness of modified binders. Furthermore, studies investigating the effect of recycled EVA modified binders have demonstrated promising results, which was evidential that reclaimed plastomers also have the potential to improve the performance of modified binders at high service temperatures $(9,10)$. Research regarding PE and PP modified binders has demonstrated similar findings, such as that increased complex modulus and reduced phase angle generate better resistance to permanent deformation. However, it was also noted in the literature that the addition of plastomeric modifiers commonly leads to more brittle behavior of $\mathrm{AC}$, thus exhibiting poor low temperature performance $(11,12)$. Consequently, coupling agents have been used with plastomers in order to eliminate the drawbacks related to the chemical and physical properties of plastomeric polymers (13). A study conducted by Yuanita et al., (11) demonstrated that the addition of lignin to PP leads to better compatibility between the base bitumen and the polymer. The findings of Bala et al., (12) also demonstrated that PE/nanosilica modified binders possess better morphological properties as well as improved low temperature performance.

In contrast to the plastomeric polymers, elastomeric polymers can resist permanent deformation and also demonstrate the ability to recover elastically after being loaded and when exposed to low temperatures (14). Elastomers that contain styrenic blocks such as Styrene-butadiene-styrene (SBS), Styrene-butadiene-rubber (SBR) and Acrylate-styreneacrylonitrile (ASA) were found to be the most suitable modifiers since they extend to improve both the high temperature and low temperature performance characteristics of AC (15-17). According to Airey and Kok et al., $(14,18)$, styrene block copolymers ensure higher strength and better rutting resistance due to the presence of polystyrene end-blocks, while the formation of polybutadiene mid-blocks is responsible for the better elastic properties. SBS 
and SBR copolymers have been investigated extensively by a number of researchers and their findings corroborated their positive influence such as increased aging resistance, prevention of high temperature rutting and low temperature fatigue failures of pavement roads $(15,19$, 20). Ali et al., (17) investigated the morphology and rheological properties of ASA modified binders and their findings validated the advancements in the rheological properties. Although polymer-modified bitumen offers promising results, many researchers have noted a major shortcoming of the modification process, which is the compatibility issue between the polymer and bitumen $(21,22)(23)$. According to Al-Mansob et al., (24) the incompatibility is associated with the occurrence of phase separation due to the differences in density, molecular weight and solubility between the polymer and asphalt. Lu et al., (25) further stated that the phase separation is governed by the chemical composition of the bitumen and the characteristics of the polymer. Due to the shortcomings of the polymer modified bitumen, researchers have gravitated towards the investigation of the potential of nano-materials and nanocomposite materials as modifiers to AC.

Nanomaterials have been rapidly incorporated in pavement engineering and utilized as direct modifiers to base $\mathrm{AC}$ or are considered as polymer/nanomaterial composites with the aim of eliminating the drawbacks of virgin asphalt and certain polymeric modifiers (26). The role of nanomaterials in asphalt modification is not only to improve the rheological properties but also to enable better dispersion, improve aging resistance and allow stability and compatibility of modified $\mathrm{AC}$ due to the unique properties of nanomaterials, such as increased surface area to volume ratio and the quantum effects resulting from spatial confinement $(27,28)$. Positive effects of modifying AC with well-known nanomaterials such as carbon nanotubes (CNT), nanoclay and nanosilica have been reported in numerous studies (29-31). Arabani et al., (32) and Ziari et al. (33) conducted research on CNT-modified asphalt binders and mixtures and concluded that the CNT modifiers enhanced the mechanical properties and also improved the aging resistance and self-healing mechanism of binders and hot mix asphalt (HMA). According to Crucho et al., (4) and You et al., (34), nanoclay modified binders enhance the stiffness and elasticity of AC; however, due to the limited enhancement in the elastic behavior of AC, nanoclay is more frequently used as a second modifier to polymer modified AC. Jun et al., (28) stated that the addition of a small amount of nanoclay into SBS modified binders can enhance the thermal properties of AC both at high and low temperatures while also improving the compatibility between the polymer and bitumen. Numerous studies have reported that, based on its cost effectiveness and notable enhancements in physical and rheological properties, nanosilica is considered as one of the most substantial advancements in asphalt modification $(26,28)$. Studies conducted by You et al., (34) and Yao et al., (35) discovered that $2 \%$ to $4 \%$ use of nanosilica by the weight of bitumen can reduce the rut depth up to $50 \%$. Additionally, Arabani et al., (36) achieved remarkable enhancement in fatigue resistance of up to $37 \%$. Nanosilica has also been utilized in numerous studies in order to build new polymer nanocomposites that can perform better over a longer life span. The drawbacks of well-known polymers such as SBS, PP and PE were found to be satisfactorily recovered with the addition of nanosilica (37-39).

Polymer/nanocomposite modified AC is considered to be the latest advancement in the field of pavement engineering that facilitates the design of roads with superior performance and increased durability (6). Unlike polymeric modifiers, polymer nanocomposites are relatively new, not readily available and have received limited attention in the literature (3). ASA and nano silica have previously been utilized as sole modifiers to AC. Besides the positive 
influence of utilizing these materials, major shortcomings such as the stability problem due to phase separation phenomena with ASA modified asphalt cement has also been reported in a previously conducted study (17). The current research aims to overcome the stability concern by adding nano silica to ASA modified AC and also aims to investigate the effectiveness of the modification process regarding to high temperature performance characteristics under unaged and short-term aged conditions.

\section{Experimental Procedures}

\subsection{Materials and Sample Preparation}

Materials used for the modification of the base binder of 80/100 penetration grade were ASA and nanosilica. ASA was in the form of a white powder and was obtained from Shijiazhuang Changhang Import \& Export Trading (Shijiazhuang, China). Nanosilica particles were in the form of a white powder, spherical in shape and the average particle size was 30-50 nm.

The hot melting method was used to blend base AC with ASA at 5\% concentration and adding nano silica by 3,5 and $7 \%$ by the weight of bitumen to form ASA/Si composite modified binders. ASA is an elastomeric polymer which was previously investigated by Ali et al., (17) as a sole modifier to asphalt cement. According to the findings of their study, the optimum enhancement in physical and rheological properties of asphalt cement was achieved at $5 \%$ ASA by the weight of bitumen modification to asphalt cement. Findings of their study formed the foundations to the current study by adding nano silica in the blend to form a different polymer-nanocomposite modified asphalt cement (PNC) to mitigate certain drawbacks of polymer modified asphalt cement (PMAC) and to further improve the performance characteristics. Nano silica particles were added at 3, 5 and $7 \%$ by the weight of PMAC as suggested by numerous researchers that adding nanomaterials in small proportions typically between $2 \%-5 \%$ can enhance performance characteristics of asphalt cement significantly (31). The blending process was performed with a Silverson high shear mixer at a shear rate of 1500 rotations per minute (rpm) at a constant temperature of 165 ${ }^{\circ} \mathrm{C} \pm 1$. In order to ensure fine dispersion of particles and hence the homogeneity of the prepared blends, samples were taken every 30 minutes and investigated by the ring and ball softening point test. Stabilization of the softening point values indicated that the optimum duration for the blending process was 60 minutes.

\subsection{Temperature Susceptibility}

Asphalt is a thermoplastic material, meaning that its physical properties are time and temperature dependent. As the physical properties of asphalt change at elevated temperatures, its consistency and temperature susceptibility are described by two parameters called the penetration index (PI) and pen-vis number (PVN) (40). The PI was calculated using the penetration value at $25{ }^{\circ} \mathrm{C}$ and softening point test results by eq. 1 . PVN was calculated by eq. 2 based on the penetration and rotational viscosity test results at reference temperatures of $25^{\circ} \mathrm{C}$ and $135^{\circ} \mathrm{C}$, respectively (24).

$\mathrm{PI}=\frac{1952-500 \log (\mathrm{Pen} 25)-20 \mathrm{~S} . \mathrm{P}}{50 \log (\mathrm{Pen} 25)-\mathrm{S} . \mathrm{P}-120}$ 
Where Pen(25) is the penetration test result at $25^{\circ} \mathrm{C}$ in one tenths of a millimeter and S. P is the ring and ball softening point test result in ${ }^{\circ} \mathrm{C}$.

$\mathrm{PVN}=\frac{\log \mathrm{L}-\log \mathrm{X}}{\log \mathrm{L}-\log M} \times 1.5$

Where $\mathrm{L}$ is the rotational viscosity value at $135^{\circ} \mathrm{C}$ for a $\mathrm{PVN}$ of 0.00 ,

$\mathrm{L}=4.25800-0.79670 \operatorname{LogPen}$

$\mathrm{M}$ is the rotational viscosity value at $135^{\circ} \mathrm{C}$ for a PVN of -1.50 ,

$\mathrm{M}=3.46289-0.61094 \operatorname{LogPen}$

$\mathrm{X}$ is the rotational viscosity value at $135^{\circ} \mathrm{C}$ and LogPen is the logarithmic penetration value for bitumen at $25^{\circ} \mathrm{C}$.

\subsection{Storage Stability}

The storage stability test was conducted using aluminum foil tubes with a diameter of $30 \mathrm{~mm}$ and a height of $160 \mathrm{~mm}$. The tubes were filled with bitumen and placed vertically in the oven at $163 \pm 5{ }^{\circ} \mathrm{C}$ for 48 hours, followed by resting at room temperature to cool down. The top third and bottom thirds of the tube were cut and bitumen was taken to perform the softening point test.

\subsection{Rotational Viscosity}

The viscosity is used in the determination of the mixing and compaction temperatures for hot mix asphalt (HMA) design (17). The test was performed according to ASTM D4402 in a range of temperatures from $120{ }^{\circ} \mathrm{C}$ to $180{ }^{\circ} \mathrm{C}$ by $15^{\circ} \mathrm{C}$ increments in order to observe the variation of viscosity at elevated temperatures for the base and modified binders. The readings were taken when the measurements were stabilized and then the temperature was increased to the next increment. The test was conducted using a Brookfield rotational viscometer with spindle number 4 set to a constant speed of $20 \mathrm{rpm}$.

\subsection{FT-IR}

The Fourier Transform Infrared Spectroscopy (FT-IR) for ASA/Nanosilica composite modified bitumens was conducted to evaluate the formation of chemical bonding between the polymer nanocomposite modifier and the base bitumen as well as to identify the formation of functional groups. FT-IR spectroscopy was conducted in the wavenumber range of 4000 $\mathrm{cm}^{-1}$ to $600 \mathrm{~cm}^{-1}$ at room temperature. 


\subsection{Simulation of Short-Term Aging}

A rolling thin film oven (RTFO) was used to simulate the conditions of short-term ageing that occurs during the production and construction stages of the HMA. The standard test procedure (ASTM D2872) specifies that 35 grams of bitumen should be placed in cylindrical open mouthed bottles and then placed into a preheated carousel equipped oven at $163{ }^{\circ} \mathrm{C}$, which rotates under air blown pressure at $15 \mathrm{rpm}$ for 85 minutes. The samples were then used for the physical and rheological testing of the RTFO-aged bitumen. The significance of the procedure is that it provides an insight into the binder 'as laid' properties (41).

\subsection{Dynamic Shear Rheometer (DSR)}

The rheological behavior of asphalt cement was characterized by its vicious and elastic properties at intermediate and high temperatures. DSR was used to conduct frequency sweep and multiple stress creep recovery tests (MSCR) in accordance with AASHTO T315 and ASTM: D7405 - 15, respectively. The tests were conducted with the binder samples that were placed between the two parallel plates of the DSR $(25.0 \mathrm{~mm}$ in diameter and $1.0 \mathrm{~mm}$ spacing between plates). Frequency sweep tests were performed to measure fundamental parameters such as the complex modulus $\left(\mathrm{G}^{*}\right)$ and the phase angle $(\delta)$, which determined the stiffness of the samples. The tests were performed under strain-controlled conditions, while the temperature was shifted from $46{ }^{\circ} \mathrm{C}$ to $82{ }^{\circ} \mathrm{C}$ with increments of $6{ }^{\circ} \mathrm{C}$. To maintain stable temperature conditions within $\pm 0.1{ }^{\circ} \mathrm{C}$ as suggested by SHRP, a temperature unit that consisted of a fluid bath system was used. The shearing action was achieved by the movement of upper plate at nine different frequencies for each elevated temperature in the range of $0.159 \mathrm{~Hz}-15.92 \mathrm{~Hz}$. $\mathrm{G}^{*}$ and $\delta$ outcomes of the frequency sweep tests were used to construct master curves for base and modified asphalt binders. Isochronal plots at varying temperatures for $0.159 \mathrm{~Hz}$ and $15.92 \mathrm{~Hz}$ and the rutting resistance parameter were further plotted in order to evaluate the effect of the modification process on the performance characteristics of AC.

The multiple stress creep recovery (MSCR) test was utilized to determine the nonrecoverable creep compliance $\left(\mathrm{J}_{\mathrm{nr}}\right)$ and the percentage of recovery $(\% \mathrm{R})$ for the base and modified AC under RTFO aged condition. ASTM: D7405 - 15 procedure was used for MSCR testing. The test was conducted at $64{ }^{\circ} \mathrm{C}$ with two different stress levels of $100 \mathrm{~Pa}$ and $3200 \mathrm{~Pa}$. DSR with a plate of $25 \mathrm{~mm}$ in diameter and $1 \mathrm{~mm}$ gap was used to apply a haversine shear load on the sample for a period of 1 second. Then the load is removed and the sample was allowed to recover for a period of 9 seconds in order to complete 1 cycle (3). 10 cycles for each stress level were conducted where the first 10 cycles were performed at $100 \mathrm{~Pa}$ and the second 10 cycles were performed at $3200 \mathrm{~Pa}$ stress levels. Outcomes of the test were used to compute Jnr and \%R using eq 5 and 6, respectively.

$J_{n r}(\sigma, N)=\frac{\varepsilon_{r}-\varepsilon_{o}}{\sigma}$

Where, $J_{n r}$ is the non-recoverable creep compliance, $\varepsilon_{r}-\varepsilon_{o}$ is the non-recoverable strain at the end of rest period, $\sigma$ is the applied stress level and $N$ is the number of cycles. 
$\% R=\frac{\varepsilon_{1}-\varepsilon_{10}}{\varepsilon_{1}} \times 100 \%$

Where, $\% R$ is the percentage recovery, $\varepsilon_{1}$ is the strain at the end of 1 second creep phase and $\varepsilon_{10}$ is the strain at the end of 10 seconds creep phase.

\section{Results and Discussion}

\subsection{Physical Properties}

The effect of adding ASA/Nanosilica to the base binder was investigated using the penetration, softening point and viscosity test results. The results of the physical tests and the associated parameters evaluated based on the test results are demonstrated in Table 1. Penetration index (PI) and Penetration Viscosity Number (PVN) were the two parameters used in assessing the temperature susceptibility of AC. A PI value for base bitumen ranges from -3 to +7 , where lower values indicate a more temperature susceptible $\mathrm{AC}$ and higher values represent the opposite. As can be deduced from Table 1, the reduction in the penetration value and increase in the softening point indicated that the $\mathrm{AC}$ became stiffer with the addition of ASA/Nanosilica composite at higher concentrations. Furthermore, the increased PI and PVN numbers show that the modification process led to the improved temperature susceptibility of modified AC.

Table 1 - Physical properties of base and polymer-nano composite modified binders

\begin{tabular}{lccccc}
\hline & $\begin{array}{c}\text { Penetration } \\
(\mathbf{d m m})\end{array}$ & $\begin{array}{c}\text { Softening } \\
\text { point }\left({ }^{\circ} \mathbf{C}\right)\end{array}$ & $\begin{array}{c}\text { Viscosity @ } \\
\mathbf{1 3 5}^{\circ} \mathbf{C}(\mathbf{c p})\end{array}$ & PI & PVN \\
\hline Base AC & 89.6 & 50.5 & 474.0 & 0.468604 & -0.09302 \\
ASA/Si 3\% & 63.3 & 54.5 & 648.0 & 0.458391 & -0.02429 \\
ASA/Si 5\% & 61.1 & 55.0 & 888.0 & 0.478665 & 0.374701 \\
ASA/Si 7\% & 53.4 & 57.0 & 1050.0 & 0.571275 & 0.432553 \\
\hline
\end{tabular}

\subsection{Storage Stability}

Storage stability is an important property of modified AC that is used in the evaluation of the integrity and homogeneity of asphalt mixtures during storage and handling of $\mathrm{AC}$ in the field. Although polymer-modified AC offers significant improvement in the properties of AC, many researchers' findings have indicated that the phase separation problem due to dissimilarity between the polymer and asphalt chemistry such as solubility and density are the causes of instability and incompatibility in polymer modified AC (42). The phase separation is related to the accumulation of polymer particles in the upper section of the binder at high temperatures, which forms a stationary state. The ring and ball softening point test was used to evaluate the differences in the top and bottom sections of the conditioned samples in the aluminum foil tube, which was split into 3 equal sections. Although a difference of up $4{ }^{\circ} \mathrm{C}-4.5^{\circ} \mathrm{C}$ in softening point values between the top and bottom sections 
was considered within acceptable limits, the common perception among the researchers is that in order to classify AC as storage stable, the difference in softening points should not exceed $2.5{ }^{\circ} \mathrm{C}$ (12). A previous study conducted on ASA modified AC by Ali et al., (17) indicated that the differences in softening points between the top and bottom sections were observed to reach up to $12{ }^{\circ} \mathrm{C}$, displaying signs of phase separation between the polymer and bitumen. The results of the addition of nanosilica at 3,5 and 7\% by the weight of ASA modified AC are demonstrated in Figure 1. The storage stabilities of polymer nanocomposite samples improved as the binder to asphalt concentration was increased. Differences in softening points between the top and bottom sections were observed to be less than $2.5^{\circ} \mathrm{C}$ for $5 \%$ and $7 \% \mathrm{ASA} / \mathrm{Si}$ modified $\mathrm{AC}$, while at $3 \% \mathrm{ASA} / \mathrm{Si}$ concentration, the difference in softening points was $4.5^{\circ} \mathrm{C}$.

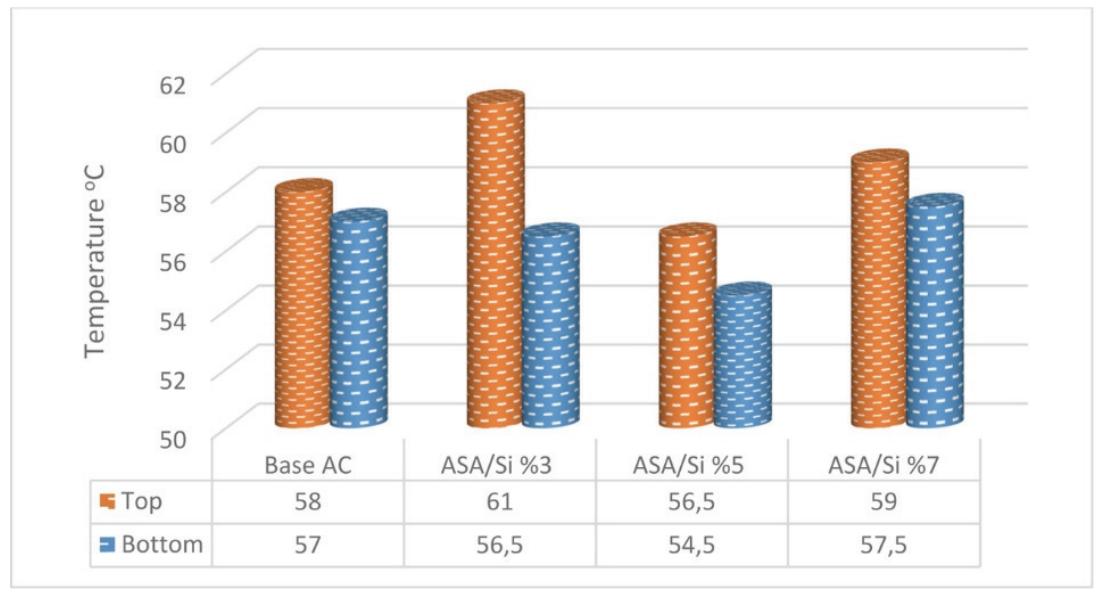

Figure 1 - Difference in softening point between the top and bottom sections

\subsection{Rotational Viscosity}

The rotational viscosity test results for unaged and short-term aged base and polymer nanocomposite modified asphalt binders are illustrated in Figure 2. The viscosity values for all samples were reduced as the test temperature increased regardless of the modifier content. Furthermore, the increase in the modifier content resulted in higher viscosities. It can also be observed that the short-term aged samples demonstrated higher viscosities compared to the unaged samples. Substantially, the RTFO-aged and unaged samples test results for rotational viscosity at $135^{\circ} \mathrm{C}$ allowed the computation of Viscosity Aging Index (VAI) using eqn. 7 (43). VAI was used to evaluate the aging resistance of base and modified binders. The results displayed in Table 2 demonstrate that the VAI numbers were successively reduced with the increase in polymer nanocomposite concentration in the $\mathrm{AC}$, indicating an improvement in the aging resistance. It is noteworthy to mention that the rotational viscosity test results are useful in the determination of the physical properties of $\mathrm{AC}$ as well as the mixing and compaction temperatures of HMA; however, the results are not indicative of significant rheological properties. 
$\mathrm{VAI}=\frac{\text { Viscosity }_{\mathrm{RTFO}}-\text { Viscosity }_{\text {unaged }}}{\text { Viscosity }_{\text {unaged }}}$

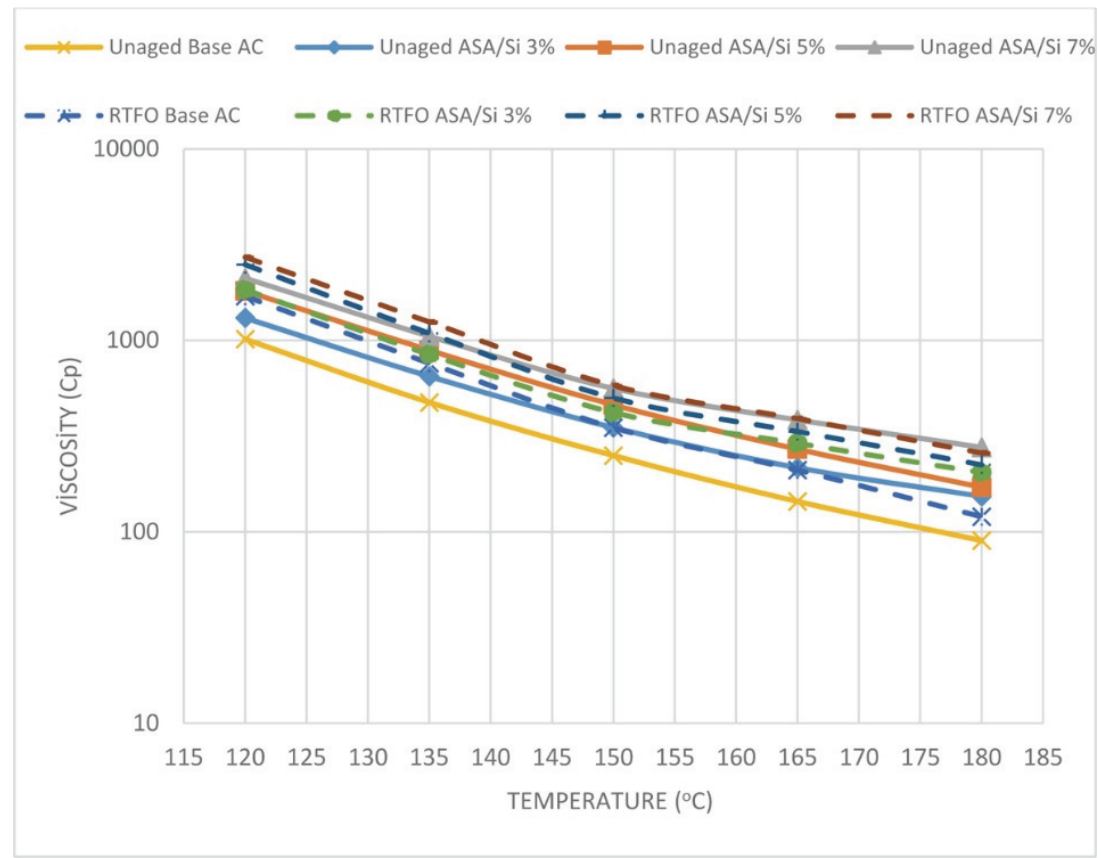

Figure 2 - Rotational viscosities for unaged and RTFO-aged base and ASA/Si modified AC

Table 2 - Viscosity Aging Index

\begin{tabular}{lccc}
\hline & $\begin{array}{c}\text { Viscosity of unaged } \\
\text { AC @135(cp) }\end{array}$ & $\begin{array}{c}\text { Viscosity of } \\
\text { RTFO aged AC } \\
\text { @135 (cp) }\end{array}$ & $\begin{array}{c}\text { Viscosity Aging } \\
\text { Index }\end{array}$ \\
\hline Base AC & 474 & 760 & 0.603 \\
ASA/Si 3\% & 648 & 844 & 0.302 \\
ASA/Si 5\% & 888 & 1088 & 0.225 \\
ASA/Si 7\% & 1050 & 1248 & 0.189 \\
\hline
\end{tabular}

\subsection{FT-IR}

The FTIR analysis was employed to observe the presence of specific chemical functional groups and bonding changes that occur when the base and modified binders were subjected to aging conditions. The FTIR investigation was performed in a spectra of wavenumbers from $4000 \mathrm{~cm}^{-1}-600 \mathrm{~cm}^{-1}$. The evidence of the formed groups can be found in the spectra along with the reference IR bands as illustrated in Figure 3. During the aging process, the chemical composition of the bitumen may change due to bonding with atmospheric oxygen. 
Carbonyl compounds and sulfoxides were formed during the chemical transformations caused by oxidative aging. Additionally, aromatic and aliphatic compounds are related to the aging of asphalt cement and therefore monitored during the aging process. In order to quantitatively analyze the changes of specific functional groups due to the aging effects and the influence of modifiers on the aging effect, the peak areas under the specific bands were measured from valley to valley for each plot at specifically selected wavenumbers of the obtained spectrum. The results of the quantitative analysis were illustrated in Figures $4 \mathrm{a}, 4 \mathrm{~b}$ and $4 \mathrm{c}$.

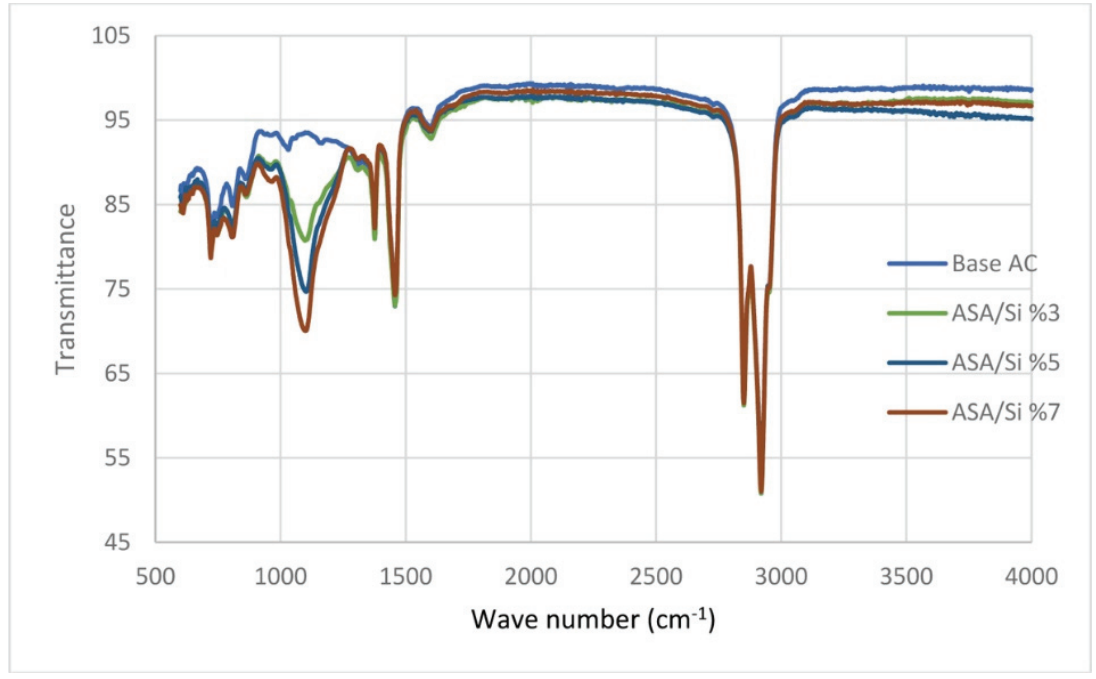

Figure 3 - FT-IR Pattern for base and ASA/Si composite binders

The aliphatic structures exist in the light fractions of bitumen. During the aging process, light components of bitumen volatiles and aliphatic chains form aromatic rings. Hence, a reduction of aliphalticity with aging was observed for all binders as illustrated in Figure 4a. It is also noteworthy to mention that the aliphalticity index of unaged modified binders decrease with the increase of modifier content. This was due to ASA and nano silica absorbing the light fractions of bitumen during the interaction process. As illustrated in Figure $4 \mathrm{~b}$, the aromaticity of base bitumen increased after aging for base and ASA/Si 3\%, which confirmed that the formation of aromatics was associated with an equivalent reduction of the aliphatic structures. However, for $\mathrm{ASA} / \mathrm{Si} 5 \%$ and $\mathrm{ASA} / \mathrm{Si} 7 \%$, a reduction in the aromatics was observed. This was associated to continued interaction between the ASA and nano silica with bitumen to absorb aromatic structures. Sulfoxides and carbonyls are considered to be the main oxidation products of bitumen aging. Sulfoxide peak appears in the FTIR graph around $1034 \mathrm{~cm}^{-1}$. Although this band was visible for the base binder, it was not apparent for the modified binders due to the overlapping phenomena of the bonds in the spectra since the silica and oxygen bonding was present within the same band wavenumbers. Another group that is associated with the aging index is the carbonyl group which appears around 1700 $\mathrm{cm}^{-1}$ in the FTIR spectrum. It can be observed from Figure 4c that, the carbonyl index increases after aging however, with the addition of modifiers, the gap between the unaged 
and aged binders was decreasing which indicated that, by increasing the amount of modifiers in the blend, the aging resistance of the asphalt was increased.

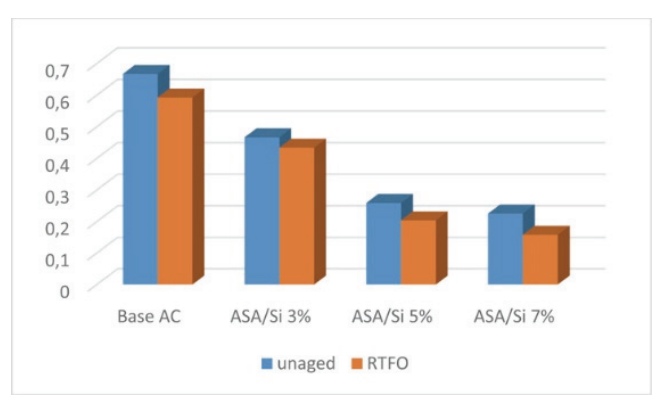

Figure 4a-Aliphatic index

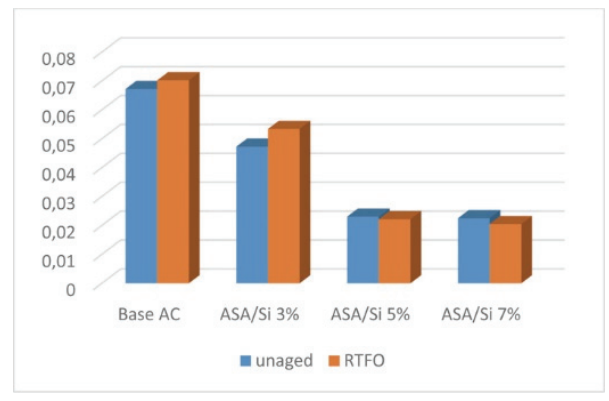

Figure $4 b$ - Aromaticity index

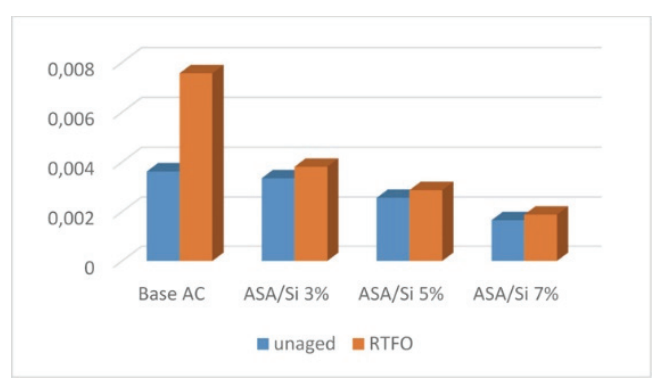

Figure 4c-Carbonyl index

\subsection{Rheological Properties}

\subsubsection{Isochronal Plots}

Isochronal plots allowed the viscoelastic features of base and modified AC such as $\mathrm{G}^{*}$ and $\delta$ versus temperature at certain frequencies to be displayed. The effects of the modification process on the stiffness and temperature susceptibility of AC were visualized in isochronal plots. As illustrated in Figures 5a-5d, G* for unaged and RTFO-aged base and polymer nanocomposite modified binders were plotted versus a range of temperatures between $46^{\circ} \mathrm{C}-$ $82{ }^{\circ} \mathrm{C}$ at $0.159 \mathrm{~Hz}$ and $15.92 \mathrm{~Hz}$. The increase in the $\mathrm{G}^{*}$ for up to $5 \% \mathrm{ASA} / \mathrm{Si}$ addition to base binder indicated that the dispersion of nanosilica in the blend led to enhancement in the strength of modified AC. The differences in $\mathrm{G}^{*}$ at $15.92 \mathrm{~Hz}$ for the base and ASA/Si modified binders at 3,5 and $7 \%$ were more remarkable than $\mathrm{G}^{*}$ at $0.159 \mathrm{~Hz}$, indicating that the influence of nanoparticles is more prominent at low frequencies and high temperatures. The isochronal plots constructed after the short-term aging procedure followed a similar trend for modified and base asphalt; therefore, the increase in the $\mathrm{G}^{*}$ was attributed to the short-term aging of the asphalt phase rather than the rearrangement of polymer/nanocomposite particles. Furthermore, the relatively small increase in the $\mathrm{G}^{*}$ of modified binders compared to the base binder was related to improved temperature susceptibility. 
The High Temperature Performance Evaluation of Polymer/Nanocomposite ...

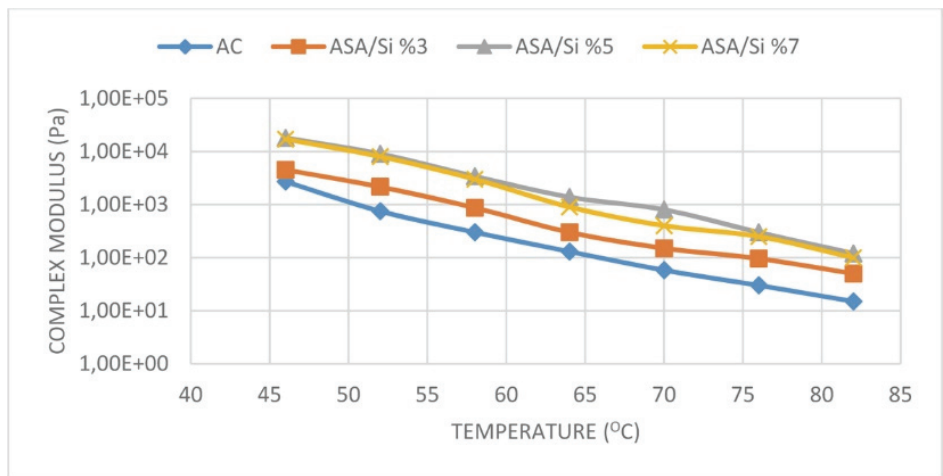

Figure $5 a$ - Isochronal plot of unaged $\mathrm{G}^{*}$ at $0.159 \mathrm{~Hz}$

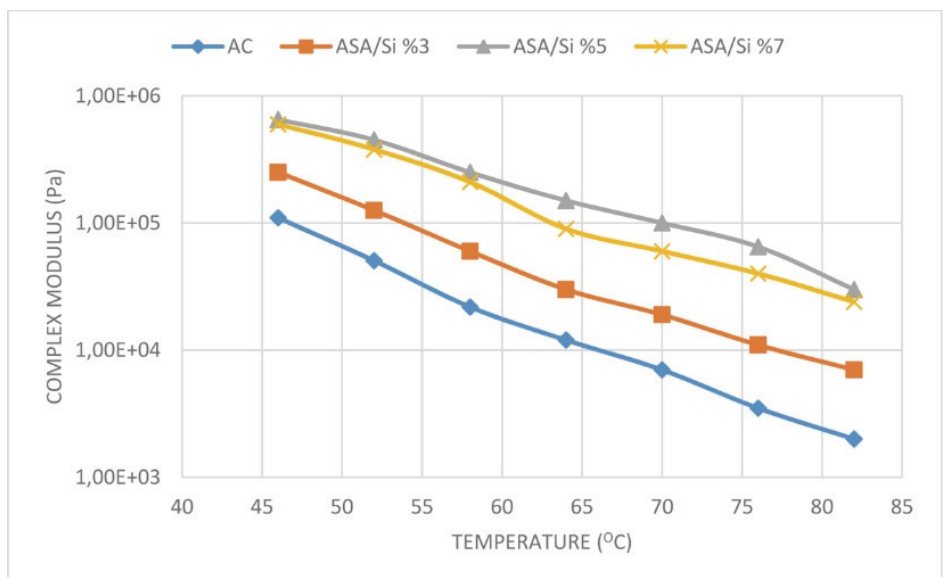

Figure $5 b$ - Isochronal plot of unaged $\mathrm{G}^{*}$ at $15.92 \mathrm{~Hz}$

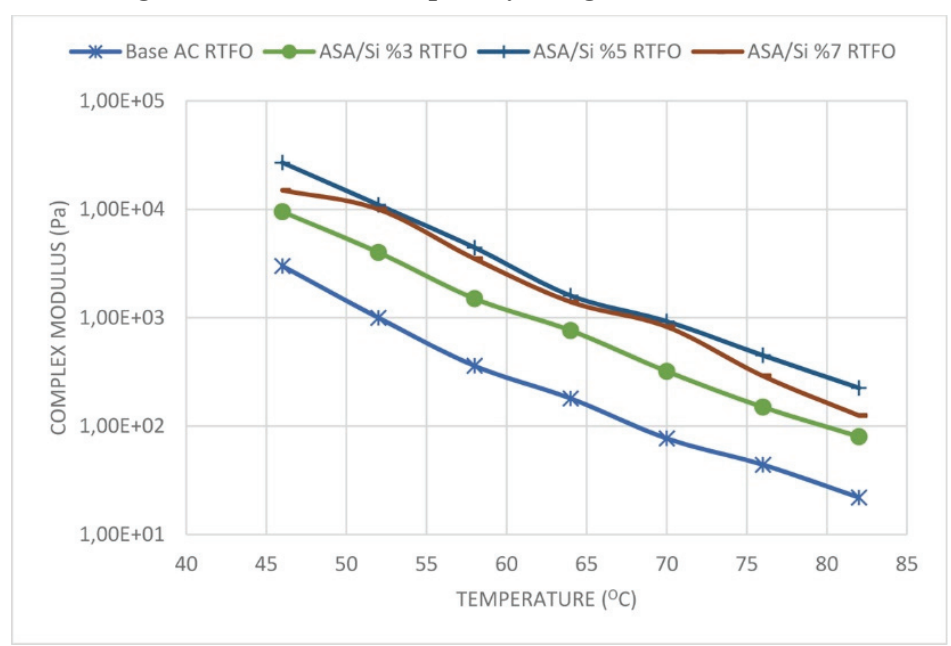

Figure 5c - Isochronal plot of RTFO aged $\mathrm{G}^{*}$ at $0.159 \mathrm{~Hz}$ 


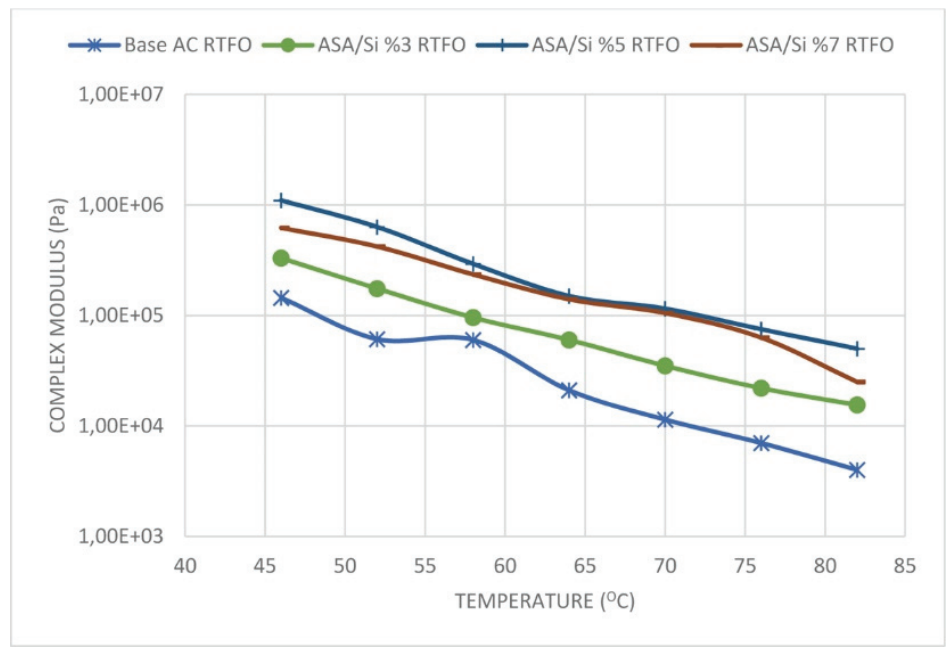

Figure 5d - Isochronal plot of RTFO aged $\mathrm{G}^{*}$ at $15.92 \mathrm{~Hz}$

\subsubsection{Master Curves}

A master curve reflects the time dependency of binders by representing rheological parameters such as $\mathrm{G}^{*}$ and $\delta$ over a range of temperatures and frequencies. Construction of the master curve involved time-temperature superposition. A reference temperature of $64{ }^{\circ} \mathrm{C}$ was selected and the rheological data at other temperatures were shifted horizontally with relevant shift factors in order to plot a smooth curve. The master curves for the $\mathrm{G}^{*}$ of base and polymer nanocomposite modified binders for the unaged and RTFO aged samples are presented in Figures $6 a$ and $6 b$, respectively. A smooth increase in the $\mathrm{G}^{*}$ was observed for modified binders up to $5 \%$ addition of ASA/Si composites, while at $7 \%$ concentration, the behavior was changed resulting in lower stiffness and therefore lower rutting resistance of AC. Similar trends were observed for both samples in unaged and under RTFO-aged conditions with a slight increase in the $\mathrm{G}^{*}$ for RTFO-aged binders corresponding to an increase in stiffness. It should be noted that previous studies that have utilized ASA and nanosilica as solitary modifiers to base AC reported improvement in $\mathrm{G}^{*}$; however, a similar trend of degradation in $\mathrm{G}^{*}$ with the addition of modifier at higher concentrations was also observed $(17,44)$.

\subsubsection{MSCR Test}

The use of the multiple stress creep recovery (MSCR) test is essential in the determination of the rutting potential of the binders. The MSCR test was utilized to measure the amount of permanent deformation during the 9 seconds resting period in the loading-unloading cycle. Non recoverable compliance $\left(\mathrm{J}_{\mathrm{nr}}\right)$ and the percentage recovery $(\% \mathrm{R})$ were the two parameters revealed by the MSCR test. A higher degree of recovery and lesser $\mathrm{J}_{\mathrm{nr}}$ were noted as desirable properties for AC. The MSCR test was conducted at $100 \mathrm{~Pa}$ and $3200 \mathrm{~Pa}$ in order to evaluate the low stress and high stress level traffic scenarios. Figure $7 \mathrm{a}$ and $7 \mathrm{~b}$ display the creep and 
creep recovery schemas for base and 3\%,5\% and 7\% ASA $/ \mathrm{Si}$ modified binders at the temperature of $64{ }^{\circ} \mathrm{C}$. From Figure 8, an increase in the elastic recovery of ASA/Si modified asphalt up to $5 \%$ concentration was observed while this increase was less for the $7 \% \mathrm{ASA} / \mathrm{Si}$ modifier content AC. At $100 \mathrm{~Pa}$ stress level, the percentage increase for the ASA/Si modifiers at 3,5 and $7 \%$ content compared to the base asphalt were $39.5 \%, 92.8 \%$ and $52.0 \%$ respectively, while at the $3200 \mathrm{~Pa}$ stress level, the percentage increase was $93.4 \%, 199.0 \%$ and $95 \%$. The $\mathrm{J}_{\mathrm{nr}}$ results illustrated in Figure 9 also demonstrated that, the non-recoverable creep was reduced after the modification process. The reduction of the $\mathrm{J}_{\mathrm{nr}}$ compared to the base asphalt were $22.0 \%, 43.5 \%$ and $17.7 \%$ for the ASA/Si 3, 5 and $7 \%$ at the $100 \mathrm{~Pa}$ stress level and they were $31.9 \%, 41.30 \%$ and $12.9 \%$ at the $3200 \mathrm{~Pa}$ stress level, respectively.

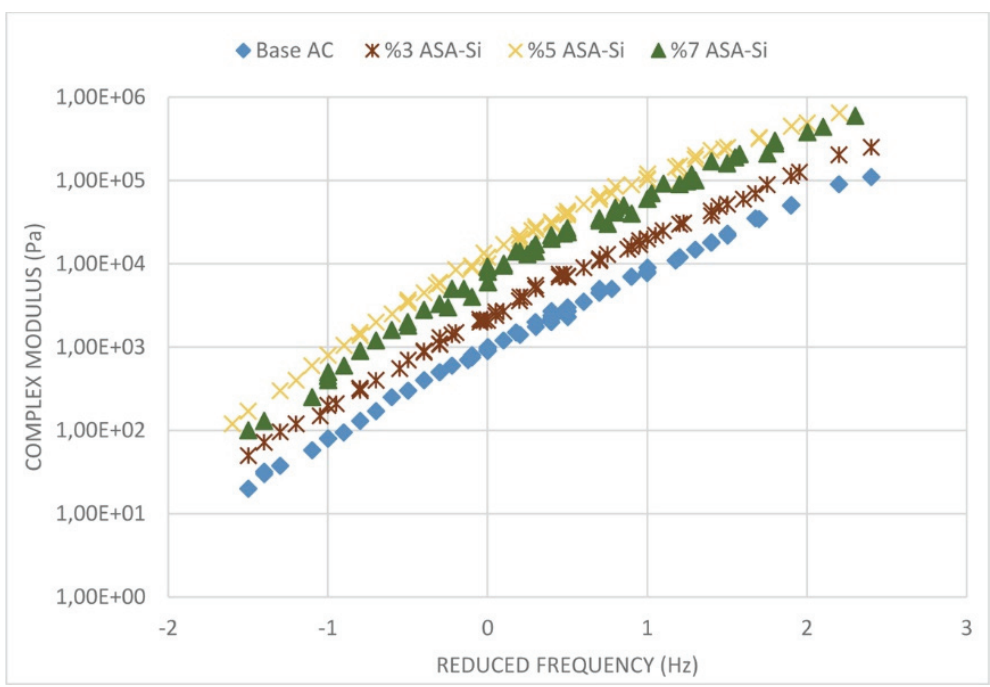

Figure 6a-Complex modulus master curve for unaged base and modified binders

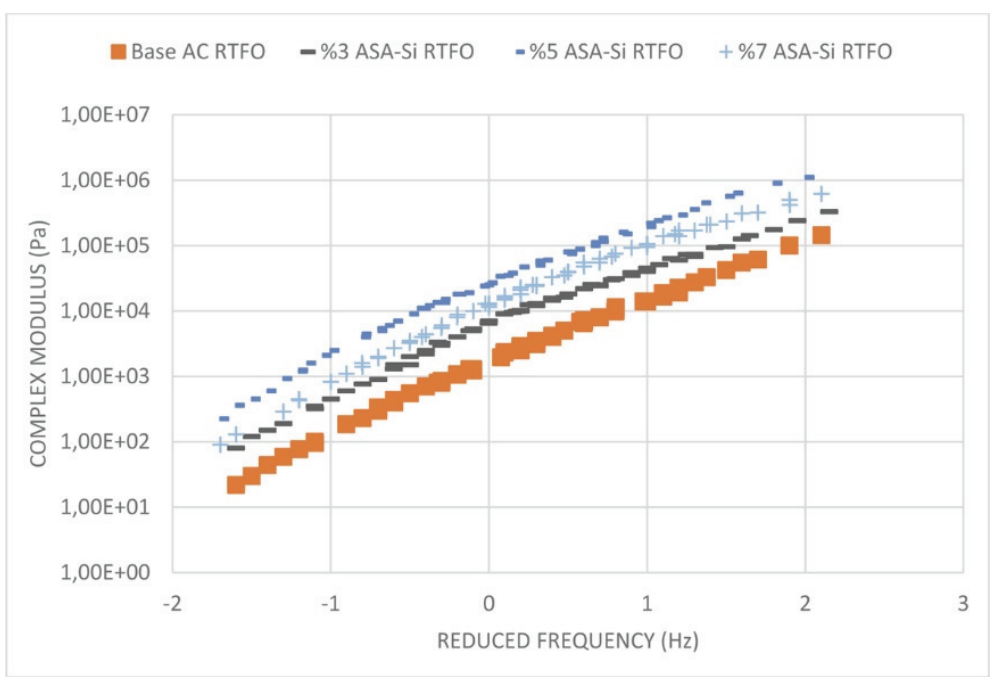

Figure $6 b$ - Complex modulus master curve for RTFO aged base and modified binders 


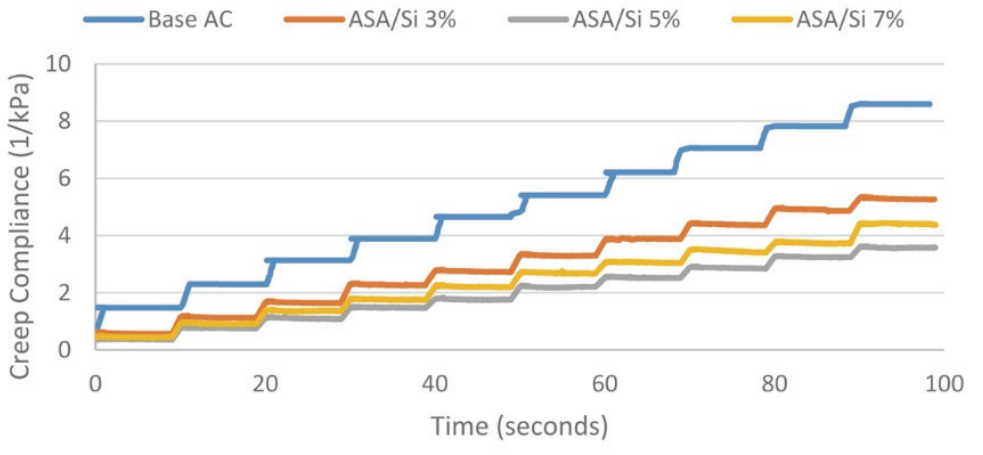

Figure $7 a$-Creep compliance at $100 \mathrm{~Pa}$

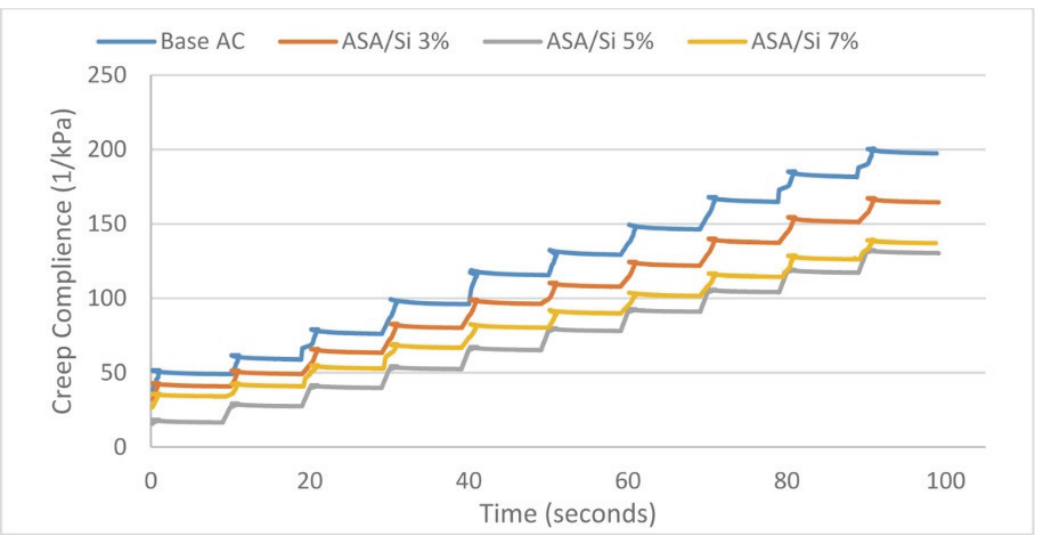

Figure $7 b$ - Creep compliance at $3200 \mathrm{~Pa}$

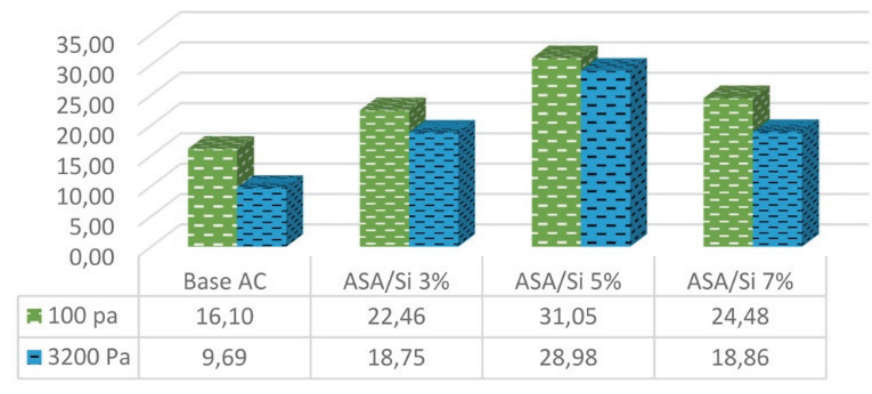

Figure 8 - Elastic recovery of base and modified binders 


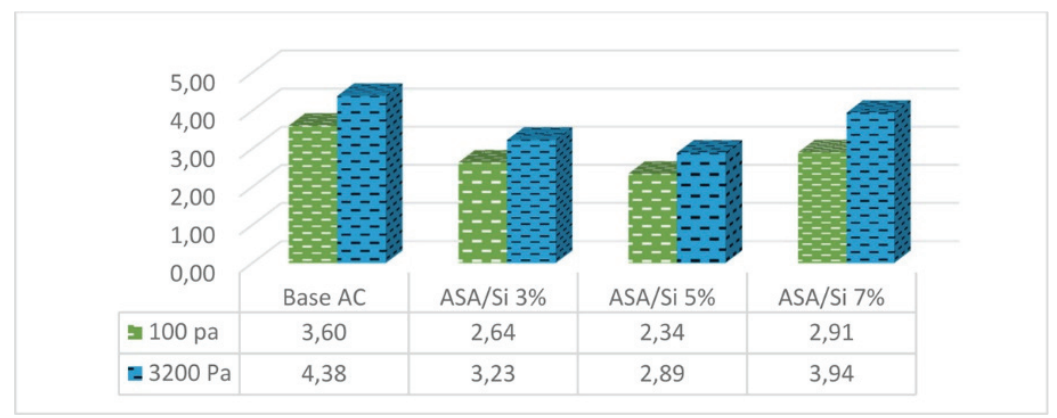

Figure 9 - Non-recoverable compliance of base and modified binders

\subsubsection{Rutting Resistance Parameter}

The formula $\mathrm{G}^{*} / \sin \delta$ was used to explain the rutting resistance (permanent deformation) of asphalt at high temperatures. Al Mansob et al. (24) stated that the rutting parameter reflects the resistance of $\mathrm{AC}$ to permanent deformation when subjected to dynamic loading and the relative amount of energy dissipated into non-recoverable deformation during the loading cycle. According to Superpave standards, at a loading rate of $1.592 \mathrm{~Hz}$, a minimum of $1 \mathrm{kPa}$ is the allowable requirement for an unaged sample of binder. The rutting parameter was evaluated in a range of temperatures between $46^{\circ} \mathrm{C}-82{ }^{\circ} \mathrm{C}$ at $1.592 \mathrm{~Hz}$ using the $\mathrm{G}^{*}$ and $\delta$ outcomes of the frequency sweep test results. As illustrated in Figure 10, $\mathrm{G}^{*} / \sin \delta$ was the lowest for base AC. Binders containing ASA/Si composites up to $5 \%$ by the weight of bitumen demonstrated the highest $\mathrm{G}^{*} / \sin \delta$ value, while the addition of polymer nanocomposite above $5 \%$ concentration led to reduced $\mathrm{G}^{*} / \sin \delta$. The compatibility problem between the polymer nanocomposite and the binder was considered to be the factor leading to the reduction in rutting resistance parameter at $7 \% \mathrm{ASA} / \mathrm{Si}$ concentration. In general, the rutting performance of the modified binders was increased compared to the base binder and satisfied the minimum requirement of $1 \mathrm{kPa}$ at $1.592 \mathrm{~Hz}$ and at $64^{\circ} \mathrm{C}$.

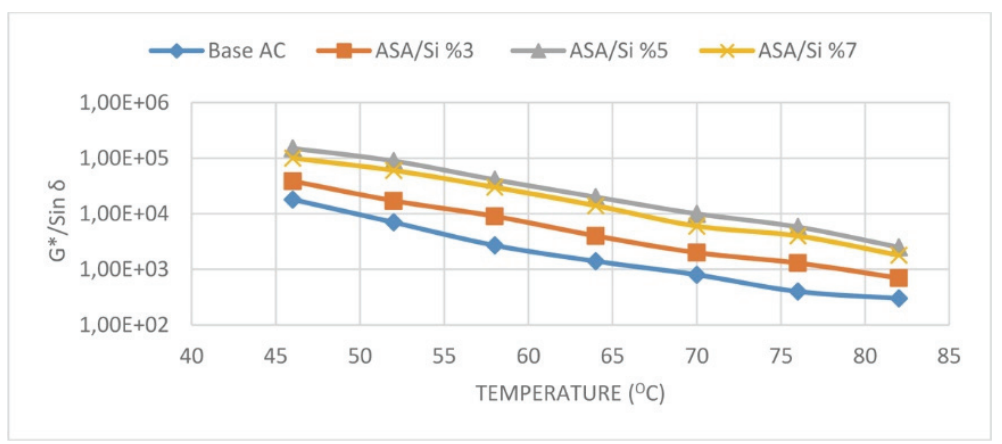

Figure 10 - Effect of temperature on rutting parameter of base and ASA/Si-modified asphalt binders 


\section{CONCLUSION}

The influence of ASA/Nanosilica polymer nanocomposite modifier were evaluated under unaged and RTFO aged conditions with respect to physical, chemical and rheological properties. ASA was used in 5\% concentration whereas, the addition of nanosilica was 3,5 and $7 \%$ by the weight of AC. Based on the results of the study; 1 . The physical properties of the PNC were improved and also demonstrated better aging resistance after short term aging. 2. The frequency sweep test results showed that, the stiffness of the PNC was increased leading to higher $\mathrm{G}^{*}$ and improved rutting resistance. 3. Based on the MSCRT results, higher $\mathrm{R} \%$ and lesser Jnr indicated that the materials' high temperature characteristics were improved. 4. The performance enhancement at 7\% ASA/Si composition was slightly less than that of $5 \% \mathrm{ASA} / \mathrm{Si}$ modified $\mathrm{AC}$ which was a sign of agglomeration.

In general, ASA/Si composite modified binders at all concentrations improved temperature susceptibility and rheological properties under intermediate and high temperature conditions. The reduced enhancement at 7\% ASA/Si compared to 5\% ASA/Si concentration was attributed to the occurrence agglomeration between the particles within the asphalt matrix. The present study demonstrated that ASA/Si composite binders were able to address the rutting failure of asphalt at high temperatures. It is recommended for a future study that the results of the present study be used as foundations to investigate the influence of ASA/Si composite asphalt under different asphalt concrete mixture conditions. This would enable designers and engineers to reach to a better conclusion prior to any field application.

\section{References}

[1] Ahmed AW, Said SF, Lu X, Carlsson H. Pavement performance follow-up and evaluation of polymer-modified test sections. International Journal of Pavement Engineering. 2019;20(12):1474-87.

[2] Al-Mansob RA, Ismail A, Yusoff NIM, Albrka SI, Azhari CH, Karim MR. Rheological characteristics of unaged and aged epoxidised natural rubber modified asphalt. Construction and Building Materials. 2016;102:190-9.

[3] Mahali I, Sahoo UC. Rheological characterization of Nanocomposite modified asphalt binder. International Journal of Pavement Research and Technology. 2019;12(6):58994.

[4] Crucho J, Picado-Santos L, Neves J, Capitão S. A Review of Nanomaterials' Effect on Mechanical Performance and Aging of Asphalt Mixtures. Applied Sciences. 2019;9(18):3657.

[5] Ponniah J, Kennepohl G. Polymer-modified asphalt pavements in Ontario: Performance and cost-effectiveness. Transportation research record. 1996;1545(1):151-60.

[6] Porto M, Caputo P, Loise V, Eskandarsefat S, Teltayev B, Oliviero Rossi C. Bitumen and bitumen modification: A review on latest advances. Applied Sciences. 2019;9(4):742. 
[7] Ameri M, Mansourian A, Sheikhmotevali AH. Investigating effects of ethylene vinyl acetate and gilsonite modifiers upon performance of base bitumen using Superpave tests methodology. Construction and Building Materials. 2012;36:1001-7.

[8] Brovelli C, Hilliou L, Hemar Y, Pais J, Pereira P, Crispino M. Rheological characteristics of EVA modified bitumen and their correlations with bitumen concrete properties. Construction and Building Materials. 2013;48:1202-8.

[9] Garcia-Morales M, Partal P, Navarro F, Gallegos C. Effect of waste polymer addition on the rheology of modified bitumen. Fuel. 2006;85(7-8):936-43.

[10] García-Morales M, Partal P, Navarro F, Martínez-Boza F, Gallegos C, González N, et al. Viscous properties and microstructure of recycled eva modified bitumen. Fuel. 2004;83(1):31-8.

[11] Yuanita E, Hendrasetyawan B, Firdaus D, Chalid M, editors. Improvement of polypropylene (PP)-modified bitumen through lignin addition. IOP Conf Ser Mater Sci Eng; 2017.

[12] Bala N, Napiah M, Kamaruddin I, Danlami N. Rheological properties investigation of bitumen modified with nanosilica and polyethylene polymer. International Journal of Advanced and Applied Sciences. 2017;4(10):165-74.

[13] Brasileiro L, Moreno-Navarro F, Tauste-Martínez R, Matos J, Rubio-Gámez MdC. Reclaimed polymers as asphalt binder modifiers for more sustainable roads: A review. Sustainability. 2019;11(3):646.

[14] Kok BV, Yilmaz M, Sengoz B, Sengur A, Avci E. Investigation of complex modulus of base and SBS modified bitumen with artificial neural networks. Expert Systems with Applications. 2010;37(12):7775-80.

[15] Zorn S, Mehta Y, Dahm K, Batten E, Nolan A, Dusseau R. Rheological properties of the polymer modified bitumen with emphasis on SBS polymer and its microstructure. Road Materials and New Innovations in Pavement Engineering2011. p. 41-8.

[16] Pyshyev S, Gunka V, Grytsenko Y, Bratychak M. Polymer modified bitumen. Chemistry \& Chemical Technology. 2016(10,№ 4 (s)):631-6.

[17] Ali SIA, Ismail A, Yusoff NIM, Karim MR, Al-Mansob RA, Alhamali DI. Physical and rheological properties of acrylate-styrene-acrylonitrile modified asphalt cement. Construction and Building Materials. 2015;93:326-34.

[18] Airey GD. Rheological properties of styrene butadiene styrene polymer modified road bitumens 宛. Fuel. 2003;82(14):1709-19.

[19] Fernandes MRS, Forte MMC, Leite LFM. Rheological evaluation of polymer-modified asphalt binders. Materials research. 2008;11(3):381-6.

[20] Rossi CO, Spadafora A, Teltayev B, Izmailova G, Amerbayev Y, Bortolotti V. Polymer modified bitumen: Rheological properties and structural characterization. Colloids and Surfaces A: Physicochemical and Engineering Aspects. 2015;480:390-7. 
[21] Galooyak SS, Dabir B, Nazarbeygi AE, Moeini A. Rheological properties and storage stability of bitumen/SBS/montmorillonite composites. Construction and Building Materials. 2010;24(3):300-7.

[22] Polacco G, Filippi S, Merusi F, Stastna G. A review of the fundamentals of polymermodified asphalts: Asphalt/polymer interactions and principles of compatibility. Advances in colloid and interface science. 2015;224:72-112.

[23] Yildirim Y. Polymer modified asphalt binders. Construction and Building Materials. 2007;21(1):66-72.

[24] Al-Mansob RA, Ismail A, Rahmat RAO, Borhan MN, Alsharef JM, Albrka SI, et al. The performance of epoxidised natural rubber modified asphalt using nano-alumina as additive. Construction and Building Materials. 2017;155:680-7.

[25] Lu X, Isacsson U, Ekblad J. Phase separation of SBS polymer modified bitumens. Journal of Materials in Civil Engineering. 1999;11(1):51-7.

[26] Bhargava S, Raghuwanshi AK, Gupta P. Nanomaterial Compatibility and Effect on Properties of Base Bitumen Binder and Polymer Modified Bitumen. IJISETInternational Journal of Innovative Science, Engineering \& Technology. 2016;3(6):276-82.

[27] de Mello Donegá C. The Nanoscience Paradigm:“Size Matters!”. Nanoparticles: Springer; 2014. p. 1-12.

[28] Yang J, Tighe S. A review of advances of nanotechnology in asphalt mixtures. Procedia-Social and Behavioral Sciences. 2013;96:1269-76.

[29] Ziari H, Farahani H, Goli A, Akbari T. The effect of carbon nano-tube on the fatigue life of asphalt mixtures. International Journal of Transportation Engineering. 2014;2(1):81-96.

[30] Sadeghpour Galooyak S, Palassi M, Goli A, Zanjirani Farahani H. Performance evaluation of nano-silica modified bitumen. International Journal of Transportation Engineering. 2015;3(1):55-66.

[31] Jahromi SG, Khodaii A. Effects of nanoclay on rheological properties of bitumen binder. Construction and building materials. 2009;23(8):2894-904.

[32] Arabani M, Faramarzi M. Characterization of CNTs-modified HMA's mechanical properties. Construction and Building Materials. 2015;83:207-15.

[33] Ziari H, Amini A, Goli A, Mirzaiyan D. Predicting rutting performance of carbon nano tube (CNT) asphalt binders using regression models and neural networks. Construction and Building Materials. 2018;160:415-26.

[34] You Z, Mills-Beale J, Foley JM, Roy S, Odegard GM, Dai Q, et al. Nanoclay-modified asphalt materials: Preparation and characterization. Construction and Building Materials. 2011;25(2):1072-8.

[35] Yao H, You Z, Li L, Lee CH, Wingard D, Yap YK, et al. Rheological properties and chemical bonding of asphalt modified with nanosilica. Journal of Materials in Civil Engineering. 2013;25(11):1619-30. 
[36] Arabani M, Haghi A, Tanzadeh R, editors. Laboratory study on the effect of Nano$\mathrm{SiO} 2$ on improvement fatigue performance of aged asphalt pavement. 4th International Conference on Nanostructures, Kish Island, IR Iran; 2012.

[37] Bala N, Napiah M, Kamaruddin I. Effect of nanosilica particles on polypropylene polymer modified asphalt mixture performance. Case studies in construction materials. 2018;8:447-54.

[38] Bala N, Kamaruddin I, Napiah M, Danlami N, editors. Rheological and rutting evaluation of composite nanosilica/polyethylene modified bitumen. Proceedings of the 7th International Conference on Key Engineering Materials (ICKEM 2017) held between 11th to 13th March; 2017.

[39] Rezaei S, Ziari H, Nowbakht S. Low temperature functional analysis of bitumen modified with composite of nano-SiO2 and styrene butadiene styrene polymer. Petroleum Science and Technology. 2016;34(5):415-21.

[40] Ehinola OA, Falode OA, Jonathan G. Softening point and Penetration Index of bitumen from parts of Southwestern Nigeria. Nafta. 2012;63(9-10):319-23.

[41] Yan C, Huang W, Tang N. Evaluation of the temperature effect on Rolling Thin Film Oven aging for polymer modified asphalt. Construction and Building Materials. 2017;137:485-93.

[42] Yin F, Moraes PR. Storage Stability Testing of Asphalt Binders Containing Recycled Polyethylene Materials. Phase II-A Study Report, Prepared for the Plastics Industry Association; 2018.

[43] Abutalib N, Fini EH, Aflaki S, Abu-Lebdeh TM. Investigating effects of application of silica fume to reduce asphalt oxidative aging. American Journal of Engineering and Applied Sciences. 2015;8(1):176-84.

[44] Yusoff NIM, Alhamali DI, Ibrahim ANH, Rosyidi SAP, Hassan NA. Engineering characteristics of nanosilica/polymer-modified bitumen and predicting their rheological properties using multilayer perceptron neural network model. Construction and Building Materials. 2019;204:781-99. 